\title{
Preparation of PVP/PLLA Ultrafine Blend Fibers by Electrospinning
}

\author{
Jia Xu (Corresponding author), Jinxian Wang, Xiangting Dong, Guixia Liu \& Wensheng Yu \\ Key Laboratory of Applied Chemistry and Nanotechnology at Universities of Jilin Province \\ Changchun University of Science and Technology \\ 7989 Weixing Road, Changchun 130022, China \\ E-mail: xujia_cust@163.com
}

Received: October 26, 2011

Accepted: November 16, 2011 Published: December 1, 2011

doi:10.5539/ijc.v3n4p57

URL: http://dx.doi.org/10.5539/ijc.v3n4p57

\begin{abstract}
The Polyvinylpyrrolidone (PVP) / Poly (L-lactic acid) (PLLA) ultrafine blend fibers have been prepared for the first time by electrospinning. Trichloromethane was found to be the co-solvent for electrospinning. The PVP/PLLA blend solutions in various ratios were studied for electrospinning into ultrafine fibers. The morphology of the fibers was shown by scanning electron microscope (SEM). It was found that the morphology of the fibers became finer with the content of PLLA increasing. To show the molecular interactions, PVP/PLLA fibers were characterized by Fourier transform infrared spectroscopy (FTIR). The spun ultrafine fibers are expected to be used in the native extracellular matrix for tissue engineering.
\end{abstract}

Keywords: Electrospinning, Ultrafine fiber, PVP, PLLA

\section{Introduction}

Electropinning is a simple and low-cost method for manufacturing polymer ultrafine fibers (Li et al., 2004). The ultrafine fibers produced by electrospinning method have showed amazing characteristics such as very large surface area-to-volume ratio and high porosity with very small pore size (Park et al., 2004), so they are used in biomedical area, including wound dressings (Kim et al., 2003), drug delivery (Zeng et al., 2003), tissue engineering scaffolds (Zong et al., 2003), and so on. For the tissue engineering scaffold, a highly porous microstructure with interconnected pores and large surface area is conducive to tissue ingrowth. The collected non-woven fibers mats just meet these requirements. The topology of these electrospun scaffolds closely mimics that of native extracellular matrix (ECM) (Li et al., 2005). Many materials, including natural macromolecule (Wnek et al., 2003; Chen et al., 2007), synthetic polymer (Yoshimoto et al., 2003; Yang et al., 2005) and their mixture (Nam et al., 2008), were manufactured into tissue engineering scaffold by electrospinning. Poly (L-lactic acid) (PLLA) was a biocompatible synthetic polymer which was approved by the Food and Drug Administration for specific human clinical applications, such as surgical sutures and some implantable devices, and had eximious mechanical property (Zhang et al., 2004). Its electrospinning product was increasingly used as the scaffold of tissue engineering. However, the further application of PLLA fiber in biomedical materials was hindered by its hydrophobicity. Polyvinylpyrrolidone (PVP) was also a biocompatible synthetic polymer, and was a hydrophilic polymer. So, PVP was a good material to prepare composite material with PLLA for improving the hydrophilicity of PLLA fiber.

In this study, PVP was introduced into PLLA fibers by electrospinning. The hydrophilicity of this blend fiber mat was tested.

\section{Experimental}

\subsection{Materials}

Poly (L-lactic acid) (PLLA, Mw = 5000) was obtained from Changchun Institute of Applied Chemistry. Polyvinylpyrrolidone (PVP, Mw = 1300000) was purchased from Aldrich. Trichloromethane was purchased from Tianjin Tiantai Fine Chemical Company Limited.

\subsection{Electrospinning}

Different weights of PVP (1.0, 0.5 and $0.2 \mathrm{~g})$ and different weights of PLLA (1.0, 1.5 and $1.8 \mathrm{~g}$ ) were respectively added into $8 \mathrm{ml}$ trichloromethane, the mixtures were stirred for $24 \mathrm{~h}$ at room temperature. Then, the spinning solution with different ratios by weight (PVP/PLLA: 1/1, 1/3, and 1/9) were prepared. At room 
temperature, the spinning solution was placed into a $2 \mathrm{ml}$ glass syringe with the tip of inner diameter of $1 \mathrm{~mm}$. A clamp connected with high voltage power supplier $(0-30 \mathrm{kV})$ was attached to the glass syringe. As grounded collector, a piece of aluminum foil was placed towards the tip at the distance of $27 \mathrm{~cm}$. The polymer fibers generated from the tip by high voltage flied to the grounded collector and formed the ultrafine fiber mat. The apparatus for the electrospinning experiments was similar to previous report (Gupta et al., 2005).

\subsection{Instruments}

The morphology of the electrospun fibers were observed under a Scanning Electron Microscope (SHIMADZU SSX-550) at an accelerating voltage of $15 \mathrm{kV}$. FT-IR spectra were recorded on a Nicolet Instruments Research series 5PC Fourier Transform Infrared spectrometer. The contact angle of samples was determined by a contact angle determinator (Powereach $\mathrm{JC} 2000 \mathrm{C} 2$ ).

\section{Results and discussion}

Figure 1 (A-C) showed SEM micrographs of the ultrafine fibers which were spun from the PVP/PLLA solutions with different ratios. There were some bead structures in the sample when the weight ratio of PVP and PLLA was 1:1 (Figure $1(\mathrm{~A})$ ). With the increasing content of PLLA, the beads were decreasing and the morphology of fiber became finer (Figure $1(\mathrm{~B}, \mathrm{C})$ ).

Figure 2 (A) displayed the Fourier transform infrared spectroscopy (FTIR) spectra of the electrospun pure PVP and pure PLLA fibers. The FTIR spectrum of PLLA fibers depicted characteristic absorption band at $1745 \mathrm{~cm}^{-1}$, which represent the backbone ester group of PLLA (Figure 2 A (a)). PVP fibers displayed characteristic absorption bands at $1650 \mathrm{~cm}^{-1}$ which represented the tert-amide characteristic absorption band (Figure $2 \mathrm{~A}(\mathrm{~b})$ ). Figure 2 (B) displayed the FTIR spectra of the electrospun PVP/PLLA blend fibers with different ratios. Obviously, with the increasing of PLLA, the relative strength of peak at $1745 \mathrm{~cm}^{-1}$ which belongs to carbonyl group in PLLA was increased, and the relative strength of peak at $1650 \mathrm{~cm}^{-1}$ which represent the tert-amide absorption band of PVP was decreased. The peaks position of these spectra almost did not changed. It could be explained that the molecular interaction between PVP and PLLA was weak.

Figure 3 was the relationship curve between the contact angles of PVP/PLLA blend fibers mat and the content of PLLA in the fiber. It could be seen that the contact angles of PVP/PLLA blend fibers mat was increased with the increasing of PLLA content (the decreasing of PVP content). It could be proved that the PVP content in the fiber was correlated positively with the hydrophilicity of the blend fibers mat.

\section{Conclusion}

In this study, we succeeded in preparing PVP/PLLA blended fibers by an electrospinning technique. We found that with the increasing of content of PLLA, the bead structure gradually disappeared and the morphology of fibers became finer. The hydrophilicity of fiber could be adjusted by controlling the content of PVP. It was assumed that the production would have a great potential application in the tissue engineering.

\section{References}

Chen, Z.G., Mo X.M., \& Qing F.L. (2007). Electrospinning of collagen-chitosan complex. Materials Letters, 61(16), 3490-3494. http://dx.doi.org/10.1016/j.matlet.2006.11.104

Gupta, P., Elkins, C., Long, T. E., \& Wilkes, G. L. (2005). Electrospinning of linear homopolymers of poly (methyl methacrylate): exploring relationships between fiber formation, viscosity, molecular weight and concentration in a good solvent. Polymer, 46(13), 4799-4810. http://dx.doi.org/10.1016/j.polymer.2005.04.021

Kim, S. H., Nam, Y. S., Lee, T. S., \& Park, W. H. (2003). Silk fibroin nanofiber. Electrospinning, properties, and structure. Polymer Journal, 35(2), 185-190. http://dx.doi.org/10.1295/polymj.35.185

Li, D., \& Xia, Y.N. (2004). Electrospinning of Nanofibers: Reinventing the Wheel? Advanced Materials, 16(14), 1151-1170. http://dx.doi.org/10.1002/adma.200400719

Li, W. J., Tuli, R., Okafor, C., Derfoul, A., Danielson, K. G., Hall, D.J., \& Tuan, R. S. (2005). A three-dimensional nanofibrous scaffold for cartilage tissue engineering using human mesenchymal stem cells. Biomaterials, 26(6), 599-609. http://dx.doi.org/10.1016/j.biomaterials.2004.03.005

Nam, J., Huang, Y., Agarwal, S., \& Lannutti, J. (2008). Materials selection and residual solvent retention in biodegradable electrospun fibers. Journal of Applied Polymer Science, 107(3), 1547-1554. http://dx.doi.org/10.1002/app.27063

Park, W. H., Jeong, L., Yoo, D. I., \& Hudson, S. (2004). Effect of chitosan on morphology and conformation of electrospun silk fibroin nanofibers. Polymer, 45(21), 7151-7157. http://dx.doi.org/10.1016/j.polymer.2004.08.045 
Wnek, G. E., Carr, M. E., Simpson, D. G., \& Bowlin, G. L. (2003). Electrospinning of Nanofiber Fibrinogen Structures. Nano Letters, 3(2), 213-216. http://dx.doi.org/10.1021/n1025866c

Yang, F., Murugan, R., Wang, S., \& Ramakrishna, S. (2005). Electrospinning of nano/micro scale poly(1-lactic acid) aligned fibers and their potential in neural tissue engineering. Biomaterials, 26(15), 2603-2610. http://dx.doi.org/10.1016/j.biomaterials.2004.06.051

Yoshimoto, H., Shin, Y. M., Terai, H., \& Vacanti, J. P. (2003). A biodegradable nanofiber scaffold by electrospinning and its potential for bone tissue engineering. Biomaterials, 24(12), 2077-2082. http://dx.doi.org/10.1016/S0142-9612(02)00635-X

Zeng, J., Xu, X., Chen, X., Liang, Q., Bian, X., Yang, L., \& Jing, X. (2003). Biodegradable electrospun fibers for drug delivery. Journal of Controlled Release, 92(3), 227-231. http://dx.doi.org/10.1016/S0168-3659(03)00372-9

Zhang, J. F., \& Sun, X. Z. (2004). Mechanical Properties of Poly(lactic acid)/Starch Composites Compatibilized by Maleic Anhydride. Biomacromolecules, 5(4), 1446-1451. http://dx.doi.org/10.1021/bm0400022

Zong, X., Ran, S., Fang, D., Hsiao, S. B., \& Chu, B. (2003). Control of structure, morphology and property in electrospun poly(glycolide-co-lactide) non-woven membranes via post-draw treatments. Polymer, 44(17), 4959-4967. http://dx.doi.org/10.1016/S0032-3861(03)00464-6
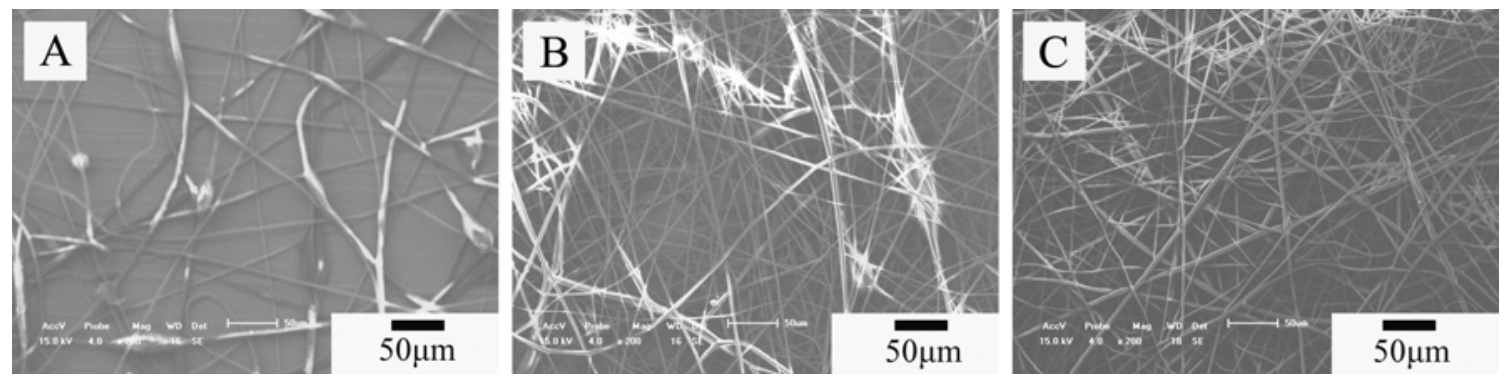

Figure 1. SEM image of the PVP/PLLA blend fibers in different weight ratios. (A) $1 / 1$; (B) $1 / 3$; (C) $1 / 9$
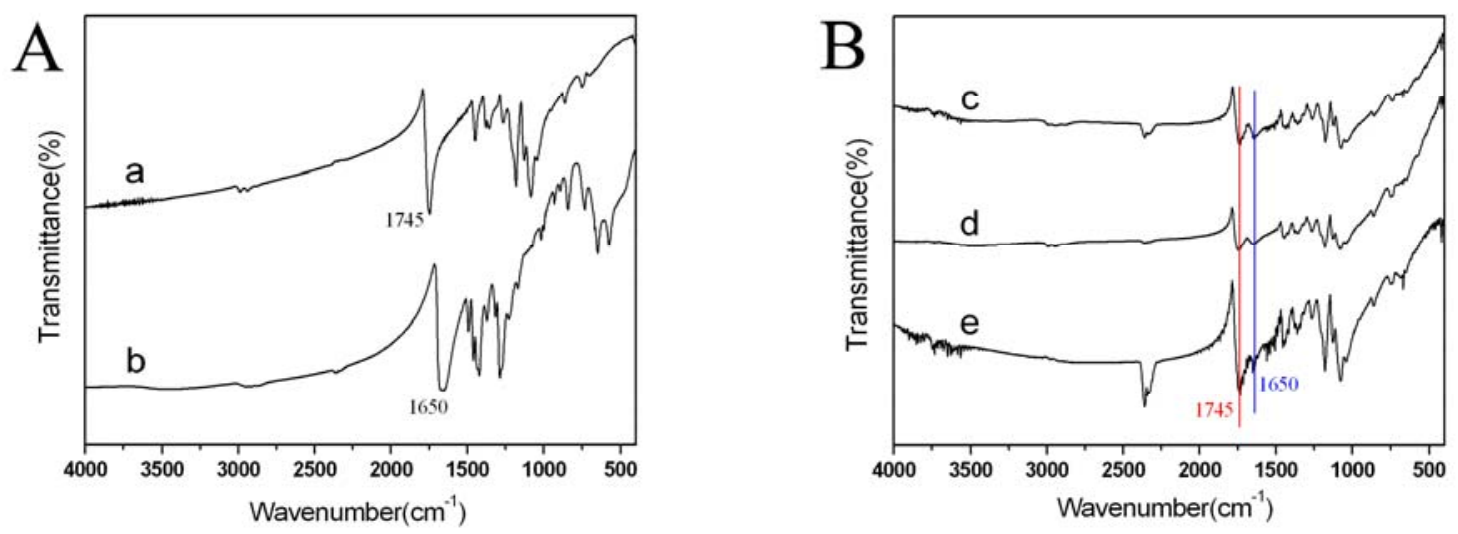

Figure 2. FTIR spectra of PVP, PLLA and PVP/PLLA blend fibers. (A) PVP (a) and PLLA (b); (B) PVP/PLLA blend fibers in different weight ratios. (c) $1 / 1$; (d) $1 / 3$; (e) $1 / 9$ 


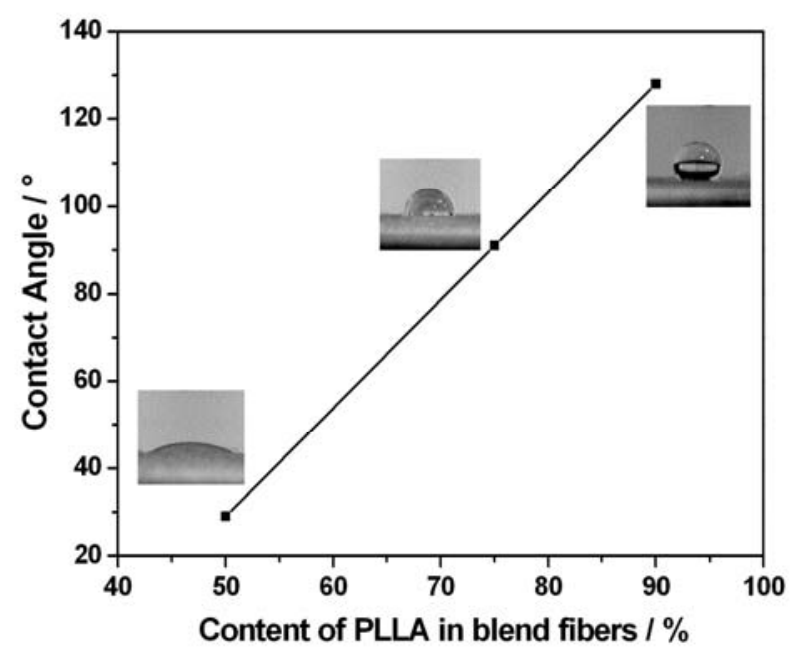

Figure 3. Contact angles of the PVP/PLLA blend fibers mat with different content of PLLA 